\title{
Higiene Sanitasi Dan Kandungan Pewarna Berbahaya Pada Keripik Pisang (Studi Pada Industri Rumah Tangga Keripik Pisang Di Kecamatan X Kabupaten Y)
}

\section{Hygiene Sanitation and Dangerous Dyes Content on Banana Chips (Study on Household Industry of Banana Chips in X District, Y Regency)}

\author{
Denah Setya Imansari ${ }^{1}$, Anita Dewi Moelyaningrum ${ }^{* 1}$, Prehatin Trirahayu Ningrum ${ }^{1}$
}

\begin{abstract}
ABSTRAK
Latar Belakang: Banyak kasus keracunan atau timbulnya penyakit karena konsumsi makanan yang keamanannya tidak terjamin, penerapan higiene sanitasi yang kurang dan penggunaan bahan kimia berbahaya seperti pewarna berbahaya yang digunakan sebagai pewarna pada keripik pisang.

Tujuan: mengkaji higiene sanitasi pengolahan keripik pisang dan kandungan zat pewarna berbahaya pada keripik pisang di Kecamatan X Kabupaten Y.

Metode: Penelitian ini merupakan penelitian deskriptif dengan pengumpulan data secara wawancara, observasi, dan uji laboratorium. Jumlah sampel merupakan total populasi sebanyak tiga industri keripik pisang dengan pekerja 40 orang dan jumlah sampel keripik pisang sebanyak 6 sampel yang dibedakan menjadi 2 yaitu keripik pisang asin dan keripik pisang manis.

Hasil: Hasil menunjukkan bahwa tiga industri memiliki higiene sanitasi cukup (100\%) dan pengetahuan pemilik terkait Bahan Tambahan Pewarna cukup (100\%), serta satu industri (33\%) memiliki higiene penjamah cukup dan dua industri (67\%) memiliki higiene penjamah kurang. Analisa pewarna semua sampel keripik pisang positif Ponceau.

Kesimpulan: Dua industri keripik pisang masih belum menerapkan higiene penjamah yang baik dan ketiga industri menggunakan pewarna ponceau.
\end{abstract}

Kata kunci: higiene sanitasi, keripik pisang, ponceau 


\title{
ABSTRACT
}

Background: many cases of poisoning or disease caused by less safety of food consumption, less applying of hygiene sanitation, and the use of dangerous chemical substances which are used as food additives in banana chips.

Objective: this research was done to review the hygiene sanitation in producing banana chips and the content of dangerous dyes in banana chips in $x$ district $y$ regency.

Methods: the method used in this research was descriptive with interview, observation, and laboratory test. The sample number was the total of population of three banana chips factories with 40 employees and 6 samples of banana chips which are divided into salty and sweet banana chips.

Results: the result showed that three factories $(100 \%)$ had fair hygiene sanitation with the owner's knowledge related to dye additives (100\%) was fair, 1 factory (33\%) had fair personal hygiene, and 2 factories (67\%) had less personal hygiene. The dyes additives analysis result of all banana chips samples was positive of Ponceau.

Conclusion: two banana chips factories have not been applied appropriate personal hygiene and three factories have banned dye additives to be used.

Keywords: hygiene sanitation, banana chips, ponceau

\author{
*Koresponden: \\ anitamoelyani@gmail.com \\ ${ }^{1}$ Bagian Kesehatan Lingkungan dan Kesehatan Keselamatan Kerja \\ Fakultas Kesehatan Masyarakat, Universitas Jember
}

\section{PENDAHULUAN}

\begin{abstract}
Saat ini sebagian besar industri pangan adalah industri pangan berskala rumah tangga. Industri Rumah Tangga Pangan (IRTP) sangat membutuhkan binaan agar produk pangan yang dihasilkan baik dan aman bagi konsumennya dengan memenuhi persyaratan mutu dan keamanan. ${ }^{1}$ Dalam kurun waktu tiga bulan, Oktober-Desember tahun 2016 sebanyak 46 insiden keracunan diperoleh data 138 media massa online. ${ }^{2}$ Berkaitan dengan proses pengolahan pangan, sanitasi sebagai penciptaan atau pemeliharaan kondisi yang mampu mencegah terjadinya kontaminasi makanan atau terjadinya penyakit yang disebabkan oleh makanan. $^{3}$
\end{abstract}

Penggunaan bahan tambahan makanan yang tepat dan sesuai dengan aturan akan menghasilkan produk dengan mutu yang diharapkan. Namun, bila penggunaannya salah dan berlebihan, akan berakibat produk tersebut tidak aman lagi dikonsumsi. Hal ini disebabkan oleh senyawa-senyawa yang tergolong bahan tambahan pangan ini kebanyakan adalah senyawa-senyawa kimia sintetis yang bila digunakan dalam jumlah berlebihan atau tidak sesuai aturan dapat berakibat fatal. ${ }^{4}$ Berdasarkan data dari BPOM, 2015 dalam metrotvnews.com (2015) ${ }^{5}$ menunjukkan 9,37 persen dari 416 sampel jajanan sekolah di DKI Jakarta tidak memenuhi syarat untuk dikonsumsi. BPOM menemukan penggunaan Methanyl yellow dalam sampel jajanan tersebut. Methanyl yellow, bahan kimia pewarna tekstil ini ditemukan dalam jajanan gulali kuning, keripik pisang, arum manis kuning, dan cone. Berdasarkan Standar Prosedur Operasional Pengolahan Pisang Tahun (2009) ${ }^{6}$, keripik pisang dalam pengolahannya tidak ditambahkan pewarna, 
baik itu pewarna sintetis ataupun pewarna alami.

Sentra produksi keripik pisang banyak terdapat di Jawa Timur, salah satunya ada di Kabupaten $Y$, hal ini dikarenakan pisang sebagai bahan baku keripik pisang merupakan komoditas yang mudah didapatkan. Menurut Dinas Perindustrian dan Perdagangan Kabupaten Y (2015) industri keripik pisang yang terkenal yaitu di Kecamatan $X$ sebanyak 3 industri karena ekspornya yang sudah dikenal di berbagai daerah. Tujuan dari penelitian ini adalah mengkaji higiene sanitasi proses pengolahan keripik pisang pada Industri Keripik Pisang, serta mengidentifikasi kandungan zat pewarna berbahaya dalam keripik pisang pada Industri Keripik Pisang di Kecamatan X Kabupaten Y.

\section{METODE}

Jenis penelitian yang digunakan dalam penelitian ini adalah deskriptif kualitatif dengan metode pengumpulan data secara observasi pada higiene sanitasi industri keripik pisang dan penjamahnya, wawancara kepada pemilik industri keripik pisang terkait bahan tambahan makanan, dan uji laboratorium secara kualitatif penentuan zat pewarna yang digunakan pada keripik pisang. Penelitian ini dilakukan di 3 industri keripik pisang di Kecamatan X Kabupaten Y. Penelitian dimulai sejak bulan Januari sampai Juli 2017. Penelitian ini menggunakan total sampling yaitu sebanyak 3 industri keripik pisang, 40 pekerja, dan 6 sampel keripik pisang.

Data yang digunakan bersumber dari data primer yaitu wawancara, observasi dan uji laboratorium. ${ }^{7}$ Data sekunder diperoleh dari telaah kepustakaan dan studi literatur. Pada penelitian ini, teknik pengolahan data dilaksanakan melalui empat tahap yaitu, editing, coding, tabulating, dan cleaning. ${ }^{8}$ Data akan disajikan dengan menggunakan tabel yang kemudian dijabarkan menjadi teks atau narasi. Data yang diperoleh berdasarkan penelitian di atas, kemudian dianalisis dengan menggunakan analisis univariat yang bertujuan untuk menggambarkan atau mendeskripsikan dari masing-masing variabel yang diteliti. ${ }^{9}$

\section{HASIL DAN PEMBAHASAN}

\section{Proses Produksi Keripik Pisang}

Tahapan proses produksi keripik pisang yaitu dimulai dengan mempersiapkan bahan baku. Bahan baku yang digunakan dalam pembuatan keripik pisang yaitu pisang jenis pisang agung, pisang rojonongko, pisang rojomolo, dan pisang kirana yang sudah tua atau matang. Pisang yang telah dipersiapkan kemudian dikupas kulitnya menggunakan pisau biasa kemudian pisang diiris tipis secara memanjang untuk jenis keripik pisang manis dan pisang diiris melingkar untuk jenis keripik pisang asin. Setelah diiris tipis, pisang ditampung dalam bak dan dicuci menggunakan air agar bersih. Kemudian irisan pisang direndam dalam pewarna selama 10 menit yang ditampung dalam bak. Setelah direndam dalam pewarna, irisan pisang ditiriskan dan siap untuk digoreng. Irisan pisang digoreng hingga cukup kering dan garing menggunakan minyak goreng dengan sistem penggorengan biasa menggunakan alat penggorengan wajan dan tungku api. Setelah keripik pisang sudah digoreng, keripik pisang ditiriskan agar keripik pisang kering dan tidak ada minyak goreng yang masih tersisa, setelah itu untuk jenis keripik pisang manis bisa ditaburkan gula halus atau dicelupkan ke larutan gula. Sedangkan untuk jenis keripik pisang asin, dicelupkan ke larutan garam. Tahap akhir keripik pisang disortasi dan dikemas ke dalam kemasan plastik berlabel dan siap untuk didistribusikan.

\section{Penerapan Higiene Sanitasi Pada Industri Keripik Pisang}

Gambaran mengenai higiene sanitasi keripik pisang pada industri keripik pisang di Kecamatan $X$ Kabupaten $Y$ yang diklasifikasikan menjadi 3 macam kategori yakni baik, cukup, dan kurang dengan persentase cukup sebanyak $100 \%$. Penilaian terhadap higiene sanitasi industri keripik pisang ini berdasarkan Depkes RI Tahun 2004. 
Tabel 1. Distribusi Frekuensi Higiene Sanitasi Keripik Pisang pada 3 Industri Keripik Pisang di Kecamatan X Kabupaten $Y$

\begin{tabular}{cllcccccc}
\hline \multirow{2}{*}{ No } & \multirow{2}{*}{$\begin{array}{l}\text { Nama Industri } \\
\text { Keripik Pisang }\end{array}$} & Kategori & \multicolumn{2}{c}{$\begin{array}{c}\text { Memenuhi } \\
\text { Syarat item }\end{array}$} & \multicolumn{2}{c}{ Tidak Memenuhi } & \multicolumn{2}{c}{ Total } \\
\cline { 4 - 9 } & & & $\mathbf{n}$ & $\mathbf{\%}$ & $\mathbf{n}$ & $\%$ & $\mathbf{N}$ & $\%$ \\
\hline 1 & Industri A & Cukup & 21 & 60 & 14 & 40 & 35 & 100 \\
2 & Industri B & Cukup & 18 & 51 & 17 & 49 & 35 & 100 \\
3 & Industri C & Cukup & 20 & 57 & 15 & 43 & 35 & 100 \\
\hline
\end{tabular}

Tabel 2. Distribusi Frekuensi Higiene Sanitasi Penjamah pada 3 Industri Keripik Pisang di Kecamatan $X$ Kabupaten $Y$

\begin{tabular}{|c|c|c|c|c|c|c|c|c|c|}
\hline \multirow{3}{*}{ No } & \multirow{3}{*}{$\begin{array}{l}\text { Nama Industri } \\
\text { Keripik Pisang }\end{array}$} & \multicolumn{6}{|c|}{ Penjamah Keripik Pisang } & & \\
\hline & & \multicolumn{2}{|c|}{ Baik } & \multicolumn{2}{|c|}{ Cukup baik } & \multicolumn{2}{|c|}{ Kurang } & \multicolumn{2}{|c|}{ Total } \\
\hline & & $\mathbf{n}$ & $\%$ & $\mathbf{n}$ & $\%$ & $\mathbf{n}$ & $\%$ & $\mathbf{N}$ & $\%$ \\
\hline 1 & Industri A & 6 & 24 & 10 & 40 & 9 & 36 & 25 & 100 \\
\hline 2 & Industri B & 0 & 0 & 4 & 40 & 6 & 60 & 10 & 100 \\
\hline \multirow[t]{2}{*}{3} & Industri C & 0 & 0 & 2 & 40 & 3 & 60 & 5 & 100 \\
\hline & Total & & & & & & & 40 & $100 \%$ \\
\hline
\end{tabular}

Persentase masing-masing industri yang menggambarkan higiene sanitasi keripik pisang pada industri keripik pisang di Kecamatan $X$ Kabupaten $Y$ dapat dilihat pada Tabel 1. Tabel 1 menunjukkan bahwa 3 industri keripik pisang di Kecamatan $X$ Kabupaten $Y$ menerapkan higiene sanitasi keripik pisang dengan cukup dan memenuhi persyaratan item-item tertentu.

Gambaran mengenai higiene penjamah keripik pisang pada industri keripik pisang di Kecamatan $X$ Kabupaten $Y$ yang diklasifikasikan menjadi 3 kategori yakni baik, cukup, dan kurang. Nilai total menunjukkan bahwa higiene penjamah keripik pisang di industri A 40\% tergolong cukup, sedangkan higiene penjamah keripik pisang di industri $B$ dan industri C $60 \%$ tergolong kurang. Hasil dari penilaian higiene penjamah keripik pisang dari masing-masing industri dapat dilihat pada Tabel 2. Tabel 2 menunjukkan bahwa higiene penjamah keripik pisang di 2 industri masih tergolong kurang.

\section{Higiene Sanitasi Keripik Pisang Industri A}

Bahan baku terlihat cukup tua atau matang sesuai kebutuhan, bersih, tidak rusak secara fisik, dan tidak terlihat busuk. Semua jenis bahan makanan perlu mendapat perhatian secara fisik serta kesegarannya terjamin, terutama bahan-bahan makanan yang mudah membusuk atau rusak seperti daging, ikan, susu, telur, makanan dalam kaleng, buah, dan sebagainya. ${ }^{10}$ Penyimpanan bahan baku secara terpelihara dan terlihat bersih, penempatannya terpisah dari makanan jadi, jarak bahan baku dengan dinding $5 \mathrm{~cm}$, jarak bahan baku dengan langit-langit $60 \mathrm{~cm}$, namun jarak bahan baku dengan dengan lantai tidak $15 \mathrm{~cm}$. Bahan baku diletakkan di lantai tanpa menggunakan alas. Kualitas air yang digunakan sudah memenuhi syarat yaitu terlihat tidak berwarna, berasa, dan berbau. Masih banyak yang tidak memenuhi syarat diantaranya yaitu lantai licin dan tidak rata, permukaan dinding tidak rata dan tidak halus, tidak ada langit-langit melainkan langsung atap yang terbuat dari seng dan asbes, namun atap sudah rapat air, dan tidak bocor. Penyimpanan keripik pisang juga sudah disajikan dengan wadah yang terlihat bersih dan aman bagi kesehatan atau tutup makanan terlihat bersih. Pada pengangkutan makanan, wadah yang digunakan pada industri A sudah terlihat bersih, utuh, kuat, dan ukurannya memadai dengan makanan yang akan diisi. Setiap wadah makanan juga sudah ditutup secara baik. Untuk proses akhir yaitu penyajian makanan, pembungkus yang digunakan yaitu plastik sudah terlihat bersih dan peralatan yang digunakan untuk proses penyajian makanan juga terlihat bersih. 


\section{Higiene Sanitasi Penjamah Industri A}

Seluruh penjamah masih kontak dengan makanan jika sedang sakit, misal batuk, pilek, influenza, diare. Dua belas penjamah selalu menutup luka (pada luka terbuka/bisul), sedangkan tiga belas penjamah lainnya tidak. Tiga belas penjamah memiliki kuku yang terlihat bersih, sedangkan dua belas penjamah lainnya tidak. Seluruh penjamah tidak memakai pakaian khusus pekerja dan hanya enam penjamah yang memakai celemek dan penutup kepala. Hal ini sejalan dengan penelitian yang dilakukan Wilis $(2013)^{11}$ tentang kondisi higiene sanitasi dan karakteristik hidangan di paguyuban PKL Wiyung Surabaya yaitu penjamah makanan menggunakan pakaian kerja berupa celemek namun tidak semua penjamah makanan menggunakannya ada yang hanya kadangkadang menggunakannya ada juga yang tidak menggunakan celemek dengan alasan tidak memiliki dan repot. Seluruh penjamah sudah melakukan kebiasaan mencuci tangan sebelum kontak dengan makanan. Seluruh penjamah tidak memakai alat/perlengkapan atau alas tangan saat menjamah makanan. Dua belas penjamah menerapkan kebiasaan tidak menggaruk anggota badan (telinga, hidung, mulut dan bagian lainnya) saat menjamah makanan, sedangkan tiga belas penjamah lainnya masih menggaruk anggota badan saat menjamah makanan. Namun, seluruh penjamah di industri A tidak merokok saat menjamah makanan. Empat belas penjamah yang menutup hidung atau mulut ketika batuk dan bersin saat menjamah makanan, sedangkan sebelas penjamah lainnya tidak selalu menutup hidung atau mulut ketika batuk dan bersin saat menjamah makanan.

\section{Higiene Sanitasi Keripik Pisang Industri B}

Bahan makanan dikatakan baik jika cukup tua atau matang sesuai kebutuhan, bebas dari pencemaran, tidak rusak secara fisik atau bahan kimia, dan bebas dari bibit penyakit. ${ }^{12}$ Bahan baku industri $\mathrm{B}$ terlihat cukup tua atau matang sesuai kebutuhan, terlihat bersih, tidak rusak secara fisik, dan tidak busuk. Industri B sudah menyimpan bahan baku secara terpelihara dan terlihat bersih, penempatannya terpisah dari makanan jadi, jarak bahan baku dengan langit-langit 60 $\mathrm{cm}$, namun jarak bahan baku dengan dinding tidak $5 \mathrm{~cm}$ dan jarak bahan baku dengan dengan lantai tidak $15 \mathrm{~cm}$. Bahan baku menempel dan dekat dengan dinding dan diletakkan di lantai tanpa menggunakan alas. Industri B sudah tersedia tempat mencuci tangan, tempat mencuci peralatan, dan tempat pencucian bahan makanan, namun dapur tidak memiliki cerobong asap, tempat sampah tidak terbuat dari bahan yang kuat, tidak mempunyai tutup dan tidak memakai kantong palstik. Tempat sampah terbuat dari anyaman bambu yang terbuka. Selain itu, saluran pembuangan air limbah tidak tertutup, dan masih ada serangga dan tikus di tempat pengolahan. Pada penyimpanan keripik pisang yang sudah jadi, industri B sudah memenuhi syarat yaitu terlindung dari debu, bahan kimia berbahaya, serangga, tikus, dan hewan lainnya. Pada pengangkutan makanan, wadah yang digunakan sudah terlihat bersih, utuh, kuat, dan ukurannya memadai dengan makanan yang akan diisi. Setiap wadah makanan juga sudah ditutup secara baik. Untuk proses akhir yaitu penyajian makanan, pembungkus yang digunakan yaitu plastik sudah terlihat bersih dan peralatan yang digunakan untuk proses penyajian makanan juga terlihat bersih

\section{Higiene Sanitasi Penjamah Industri B}

Seluruh penjamah masih kontak dengan makanan jika sedang sakit, misal batuk, pilek, influenza, diare. Dua penjamah selalu menutup luka (pada luka terbuka/bisul), sedangkan delapam penjamah lainnya tidak. Empat penjamah memiliki kuku yang terlihat bersih, sedangkan enam penjamah lainnya tidak. Selain itu, seluruh penjamah juga tidak memakai pakaian khusus pekerja dan seluruh penjamah tidak memakai celemek dan penutup kepala. Hal ini sejalan dengan penelitian yang dilakukan oleh Baluka $(2015)^{13}$ tentang praktek kebersihan dan kontaminasi makanan di fasilitas pelayanan makanan di Uganda yaitu karyawan tidak memakai seragam atau baju kerja, karyawan juga tidak memakai penutup kepala atau topi saat menjamah makanan. Seluruh penjamah sudah 
melakukan kebiasaan mencuci tangan sebelum kontak dengan makanan. Pada saat kontak dengan makanan, seluruh penjamah tidak memakai alat/perlengkapan atau alas tangan saat menjamah makanan. Empat penjamah menerapkan kebiasaan tidak menggaruk anggota badan (telinga, hidung, mulut dan bagian lainnya) saat menjamah makanan, sedangkan enam penjamah lainnya masih menggaruk anggota badan saat menjamah makanan. Namun, seluruh penjamah industri B tidak merokok saat menjamah makanan. tiga penjamah yang selalu menutup hidung atau mulut ketika batuk dan bersin saat menjamah makanan, sedangkan tujuh penjamah lainnya tidak selalu menutup hidung atau mulut ketika batuk dan bersin saat menjamah makanan.

\section{Higiene Sanitasi Keripik Pisang Industri C}

Bahan baku terlihat cukup tua atau matang sesuai kebutuhan, terlihat bersih, tidak rusak secara fisik, dan tidak terlihat busuk. Sudah menyimpan bahan baku secara terpelihara dan terlihat bersih, penempatannya terpisah dari makanan jadi, jarak bahan baku dengan langit-langit $60 \mathrm{~cm}$, namun jarak bahan baku dengan dinding tidak $5 \mathrm{~cm}$ dan jarak bahan baku dengan dengan lantai tidak $15 \mathrm{~cm}$. Bahan baku menempel dan dekat dengan dinding dan diletakkan di lantai tanpa menggunakan alas. Untuk kondisi peralatan sudah tergolong cukup baik yaitu terlihat tidak rusak, tidak gompel, dan tidak retak, permukaan peralatan halus, rata, dan mudah dibersihkan, terlihat bersih sebelum digunakan, peralatan dicuci menggunakan sabun, namun peralatan yang sudah dicuci tidak ditiriskan pada rak-rak anti karat sampai kering sendiri dengan bantuan sinar matahari melainkan dilap dengan kain. Penyimpanan keripik pisang juga sudah disajikan dengan wadah yang terlihat bersih dan aman bagi kesehatan atau tutup makanan terlihat bersih. Pada pengangkutan makanan, wadah yang digunakan pada industri $\mathrm{C}$ sudah terlihat bersih, utuh, kuat, dan ukurannya memadai dengan makanan yang akan diisi, namun wadah makanan tidak ada penutup.Untuk proses akhir yaitu penyajian makanan, pembungkus yang digunakan yaitu plastik sudah terlihat bersih dan peralatan yang digunakan untuk proses penyajian makanan juga terlihat bersih. Wadah yang digunakan harus baik, utuh, kuat, ukurannya memadai dengan makananan yang akan diisi, dan setiap wadah makanan harus ditutup secara baik dan tidak banyak dibuka selama pengangkutan sampai di tempat penyajian. ${ }^{12}$

\section{Higiene Sanitasi Penjamah Industri C}

Seluruh penjamah masih kontak dengan makanan jika sedang sakit, misal batuk, pilek, influenza, diare. dua penjamah selalu menutup luka (pada luka terbuka/bisul), sedangkan tiga penjamah lainnya tidak. Seluruh penjamah memiliki kuku yang terlihat bersih, namun seluruh penjamah tidak memakai pakaian khusus pekerja dan tidak memakai celemek dan penutup kepala. Hal ini sejalan dengan penelitian yang dilakukan oleh Suwaidi $(2015)^{14}$ tentang praktik higienes di anatar penanganan makanan di Dubai yaitu pekerja memiliki kuku pendek dan bersih selalu membersihkan rambut, dan tangan selalu dalam kondisi bersih. Seluruh penjamah sudah melakukan kebiasaan mencuci tangan sebelum kontak dengan makanan. Seluruh penjamah tidak memakai alat/perlengkapan atau alas tangan saat menjamah makanan. Dua penjamah industri C menerapkan kebiasaan tidak menggaruk anggota badan (telinga, hidung, mulut dan bagian lainnya) saat menjamah makanan, sedangkan tiga penjamah lainnya masih menggaruk anggota badan saat menjamah makanan. Dua penjamah yang selalu menutup hidung atau mulut ketika batuk dan bersin saat menjamah makanan, sedangkan tiga penjamah lainnya tidak selalu menutup hidung atau mulut ketika batuk dan bersin saat menjamah makanan.

\section{Pengetahuan Pemilik Industri terkait Penggunaan Bahan Tambahan Pewarna}

Berdasarkan hasil wawancara terhadap tiga pemilik industri keripik pisang di Kecamatan $X$ Kabupaten $Y$, diketahui ketiga pemilik industri keripik pisang memiliki pengetahuan cukup terkait bahan tambahan pewarna seperti terlihat pada Tabel 3. Tabel 3 menunjukkan bahwa 3 pemilik industri keripik pisang memiliki pengetahuan cukup. 
Tabel 3. Pengetahuan Pemilik Industri Keripik Pisang Terkait Bahan Tambahan Pewarna

\begin{tabular}{|c|c|c|c|c|c|c|c|}
\hline \multirow{3}{*}{ Pemilik Industri } & \multicolumn{6}{|c|}{ Hasil wawancara } & \multirow{3}{*}{ Pengetahuan } \\
\hline & \multicolumn{2}{|c|}{ Benar } & \multicolumn{2}{|c|}{ Salah } & \multicolumn{2}{|c|}{ Total } & \\
\hline & $n$ & $\%$ & $n$ & $\%$ & $\mathrm{n}$ & $\%$ & \\
\hline Pemilik industri $\mathrm{A}$ & 6 & 60 & 4 & 40 & 10 & 100 & Cukup \\
\hline Pemilik industri B & 5 & 50 & 5 & 50 & 10 & 100 & Cukup \\
\hline Pemilik industri C & 5 & 50 & 5 & 50 & 10 & 100 & Cukup \\
\hline
\end{tabular}

Tiga pemilik industri keripik pisang memiliki pengetahuan cukup terkait bahan tambahan pewarna. Pemilik industrl A menjawab 6 pertanyaan dengan benar dari total 10 pertanyaan, sedangkan pemilik industri B dan pemilik industri $C$ menjawab 5 pertanyaan dengan benar dari total 10 pertanyaan terkait bahan tambahan pewarna. Seluruh pemilik industri keripik pisang sudah memiliki pengetahuan yang cukup tentang bahan tambahan pewarna, namun pemilik industri keripik pisang masih belum memiliki pengetahuan yang baik mengenai pewarna apa saja yang boleh atau diizinkan oleh pemerintah. Hal ini karena responden menjawab salah pada setiap pertanyaan tentang pewarna yang dilarang atau dibolehkan oleh pemerintah. Penelitian lain yang dilakukan oleh Cahyogi, Putut dan Legiono (2016) ${ }^{15}$ tentang identifikasi pewarna methyl yellow pada mi basah di Pasar Tradisional Cerme Kabupaten Banyumas Tahun 2016 menjelaskan bahwa pentingnya mengetahui tingkat pengetahuan pedagang untuk mengetahui seberapa besar pengetahuan pedagang terhadap penggunaan zat pewarna Methyl yellow sebagai bahan tambahan pangan (BTP).

Kandungan Pewarna Berbahaya dalam Keripik Pisang yang Diproduksi oleh Industri Rumah Tangga Keripik Pisang di Kecamatan X Kabupaten $Y$

Hasil uji laboratorium menunjukkan bahwa semua sampel negatif Methanyl yellow. Adapun pewarna yang digunakan pada industri A adalah pewarna Ponceau 6R, sedangan pewarna yang digunakan olek industri B dan industri C adalah pewarna Ponceau Kristal. Hasil uji laboratorium kandungan pewarna pada keripik pisang dapat dilihat pada Tabel 4 . Tabel 4 menunjukkan bahwa semua sampel keripik pisang tidak mengandung Methanyl yellow.

Sampel 1 yaitu keripik pisang asin dari industri $A$ dan sampel 2 yaitu keripik pisang manis dari industri $\mathrm{A}$ setelah ditetesi $\mathrm{HCl}$ pekat warna yang dihasilkan yaitu merah ungu, setelah ditetesi $\mathrm{H}_{2} \mathrm{SO}_{4}$ pekat warna yang dihasilkan yaitu ungu, setelah ditetesi $\mathrm{NaOH}$ warna yang dihasilkan yaitu coklat, dan setelah ditetesi $\mathrm{NH}_{4} \mathrm{OH}$ warna yang dihasilkan yaitu merah oranye.

Tabel 4. Hasil Uji Laboratorium Secara Kualitatif terhadap Kandungan Pewarna Berbahaya pada Keripik Pisang

\begin{tabular}{lccc}
\hline \multirow{2}{*}{ Jenis Sampel } & \multicolumn{3}{c}{ Pewarna } \\
\cline { 2 - 4 } & Methanyl yellow & Ponceau 6R & Ponceau kristal \\
\hline Industri A & - & + & - \\
$\quad$ Keripik pisang asin & - & + & - \\
$\quad$ Keripik pisang manis & - & - & + \\
Industri B & - & - & + \\
$\quad$ Keripik pisang asin & - & & + \\
Keripik pisang manis & - & - & + \\
Industri C & - & - & + \\
$\quad$ Keripik pisang asin & & & \\
$\quad$ Keripik pisang manis & &
\end{tabular}


Berdasarkan warna yang dihasilkan, dapat disimpulkan bahwa pewarna yang digunakan pada keripik pisang industri $A$ adalah pewarna Ponceau 6R. Sedangkan pada sampel 3 yaitu keripik pisang asin industri $B$, sampel 4 yaitu keripik pisang manis industri $B$, sampel 5 yaitu keripik pisang asin industri $C$, dan sampel 6 yaitu keripik pisang manis industri $\mathrm{C}$ setelah ditetesi $\mathrm{HCl}$ pekat warna yang dihasilkan yaitu merah, setelah ditetesi $\mathrm{H}_{2} \mathrm{SO}_{4}$ pekat warna yang dihasilkan yaitu ungu, setelah ditetesi $\mathrm{NaOH}$ warna yang dihasilkan yaitu coklat gelap, dan setelah ditetesi $\mathrm{NH}_{4} \mathrm{OH}$ warna yang dihasilkan yaitu warna sedikit berubah.

Berdasarkan warna yang dihasilkan, dapat disimpulkan bahwa pewarna yang digunakan pada keripik pisang industri $B$ dan industri $C$ adalah pewarna Ponceau kristal. Berdasarkan Peraturan Menteri Kesehatan Republik Indonesia Nomor 239/MenKes/Per/V/85 tentang Zat Warna Tertentu yang dinyatakan Bahan Berbahaya, pewarna Ponceau 6R (C.I Food Red 8) dengan Nomor Indeks warna (C.1. No.) 16290 adalah zat warna yang dinyatakan sebagai bahan berbahaya. ${ }^{16}$ Sedangkan Ponceau Kristal merupakan bentuk Ponceau 6R dalam wujud kristal.

\section{KESIMPULAN}

Kesimpulan yang didapat dari penelitian ini adalah higiene sanitasi pengolahan keripik pisang pada Industri keripik pisang di Kecamatan $X$ Kabupaten $Y$ tergolong cukup dalam penerapannya sedangkan higiene penjamah keripik pisang, pada 2 industri tergolong kurang dan 1 industri memiliki higiene penjamah yang cukup. Pengetahuan tiga pemilik industri keripik pisang di Kecamatan $X$ Kabupaten $Y$ terkait penggunaan bahan tambahan pewarna pada proses produksi keripik pisang sudah tergolong cukup. Pewarna yang terkandung dalam keripik pisang pada tiga industri keripik pisang di Kecamatan X Kabupaten $Y$ negatif Methanyl yellow, namun ditemukan pewarna Ponceau $6 \mathrm{R}$ dan Ponceau Kristal yang dilarang menurut Permenkes RI Nomor 239/Menkes/Per/V/85.

\section{ACKNOWLEDGEMENT}

Peneliti mengucapkan terima kasih kepada pemilik industri keripik pisang di 3 perusahaan yang telah memberikan izin untuk dijadikan tempat penelitian sehingga penelitian ini dapat terlaksana.

\section{REFERENSI}

1. Pengawas, B., Dan, O. \& Indonesia, R. Badan pengawas obat dan makanan republik indonesia. (2012).

2. Sentra Informasi Keracunan (SIKer) Nasional. Berita Keracunan Bulan Oktober-Desember 2016. (2016). Available at: http://ik.pom.go.id/v2016/beritakeracunan/berita-keracunan-bulanoktober-desember-2016. (Accessed: 5th April 2017)

3. Purnawijayanti, H. A. Sanitasi, Higiene, dan Keselamatan Kerja dalam Pengolahan Makanan. (Kanisius, 2001).

4. Alsuhendra dan Ridawati. Bahan Toksik dalam Makanan. (PT. Remaja Rosdakarya Offset, 2013).

5. Metrotvnews. Marak Penggunaan Zat Berbahaya, WaspadaiJajanan Sekolah ini. (2015). Available at: http://m.metrotvnews.com/news/metro/ 4KZg9LrN-marak-penggunaan-zatberbahaya-waspadai-jajanan-sekolah-ini. (Accessed: 13th June 2017)

6. Usaha, P., Pedesaan, A. \& Aldillah, R. Departemen pertanian 2009. (2009).

7. Sugiarto., Dergibson, S., Lasmono, T. S., Deny, S. Teknik Sampling. (PT.Gramedia Pustaka Utama, 2003).

8. Suyanto, B. Metode Penelitian Sosial: Berbagi Alternatif Pendekatan. (Prenada Media, 2005).

9. Nazir, M. Metode Penelitian. (Ghalia Indonesia, 2003).

10. Mundiatun., D. Pengelolaan Kesehatan Lingkungan. (Gava Medika, 2015).

11. Wilis, A. C. Kondisi Higiene Sanitasi dan Karakteristik Hidangan di Paguyuban PKL Wiyung Surabaya. J. Tata Boga 2, 11-17 (2013).

12. Departemen Kesehatan RI. Higiene Sanitasi Makanan dan Minuman. (2004). 
13. Sylvia, A. B., RoseAnn, M. \& John, B. K. Hygiene practices and food contamination in managed food service facilities in Uganda. African J. Food Sci. 9, 31-42 (2015).

14. E, A. S. A. H., Hussein, H., W, A. F., E, E. S. \& Wasfy, A. Hygienic Practices Among Food Handlers in Dubai. Int. J. Prev. Med. Reserach 1, 101-108 (2015).
15. Cahyogi, P ., L. DI PASAR TRADISIONAL CERME KABUPATEN BANYUMAS TAHUN 2016. Bul. Keslingmas 35, 216-219 (2016).

16. Peraturan Menteri Kesehatan RI. Permenkes RI Nomor 239/MenKes/Per/V/85 tentang Zat Warna Tertentu yang dinyatakan sebagai Bahan Berbahaya. (1985). 